\title{
RESPOSTA DE GENÓTIPOS DE SOJA, CULTIVADOS NO OUTONO-INVERNO, AO NITROGÊNIO E POTÁSSIO
}

\author{
Maria do Carmo de Salvo S. Novo ${ }^{1}$ \\ Roberto Tetsuo Tanaka ${ }^{1}$ \\ Hipólito A. A. Mascarenhas ${ }^{1}$ \\ Paulo Boller Gallo ${ }^{2}$ \\ José Carlos V.N. Alves Pereira ${ }^{3}$ \\ Nelson Bortoletto ${ }^{4}$
}

\section{RESUMO}

Foi avaliado, no presente experimento, conduzido nos anos de 1991 a 1993 nas Estações Experimentais do Instituto Agronômico localizadas em Mococa, Ribeirão Preto e Votuporanga, o efeito do nitrogênio e do potássio sobre a nodulação, teor de nitrogênio na parte aérea e nos grãos, de potássio nos grãos, e na produtividade da soja. Tratamentos com doses de nitrogênio na forma de uréia $\left(0,50\right.$ e $100 \mathrm{~kg} \cdot \mathrm{ha}^{-1}$ de nitrogênio), de potássio na forma de cloreto de potássio $\left(0,30\right.$ e $60 \mathrm{~kg} \cdot \mathrm{ha}^{-1} \mathrm{de}$ $\mathrm{K}_{2} \mathrm{O}$ ) e dois cultivares de soja (IAC-8 e IAC-14) foram arranjados em fatorial de $3 \times 3 \times 2$ e dispostos no campo, em três blocos ao acaso. As sementes foram tratadas com inoculante turfoso comercial na dose de $8 \mathrm{~g} . \mathrm{kg}^{-1}$ de semente. No florescimento, plantas foram avaliadas quanto à nodulação e ao teor de nitrogênio na parte aérea. No final do ciclo, avaliou-se o teor de nitrogênio e de potássio e a produtividade de grãos. Os resultados mostraram que apenas a inoculação das sementes não forneceu nitrogênio nas quantidades exigidas para maximizar a produtividade

1 Instituto Agronômico (IAC), Caixa postal 28, 13001-970 Campinas, SP. E-mail do autor correspondente: mcdsalvo@barao.iac.br

2 Estação Experimental de Agronomia de Mococa, Caixa postal 58, 13730-970, Mococa, SP.

3 Núcleo de Agronomia da Alta Mogiana, Caixa postal 271, 14001-970, Ribeirão Preto, SP.

4 Núcleo de Agronomia do Noroeste, Caixa postal 401, 15500-000, Votuporanga, SP. 
da soja. A adubação nitrogenada prejudicou a nodulação mas aumentou o teor de nitrogênio acumulado e a produtividade de grãos nas três localidades estudadas. Em Mococa, Ribeirão Preto e Votuporanga, o IAC-8 apresentou maior massa seca e número de nódulos que o IAC-14, e foram linearmente reduzidos com o aumento da dose de nitrogênio. Somente no terceiro ano, em Mococa, a massa seca de nódulos do IAC14 foi maior que a do IAC-8. O cultivar IAC-14 foi mais produtivo que o IAC-8 nos três locais estudados, sendo sua produção e o teor de nitrogênio linearmente aumentados com a adição de nitrogênio. A adição de potássio favoreceu a nodulação, mas reduziu o teor de nitrogênio acumulado. Em Mococa e Votuporanga, a adição de potássio apenas aumentou o rendimento de grãos no terceiro ano, sendo o IAC14 mais produtivo.

Palavras-chave: soja; inoculação; rizóbio; adubação; produtividade.

\section{ABSTRACT}

\section{RESPONSES OF SOYBEAN CULTIVARS TO NITROGEN AND POTASSIUM IN AUTUMN-WINTER CROP}

The effect of nitrogen and potassium on the nodulation, concentration of nitrogen and potassium in the seeds as well as yield were evaluated in the present experiment conducted during three years (1991 to 1993) at the Experimental Stations located at Mococa, Ribeirão Preto and Votuporanga. Nitrogen quantities $(0,50$ and $100 \mathrm{~kg}$ $\mathrm{ha}^{-1}$ of $\left.\mathrm{N}\right)$ in the form of urea, potassium quantities $(0,30$ and $60 \mathrm{~kg}$ $\mathrm{ha}^{-1}$ ) as potassium chloride and two cultivars ( IAC-8 and IAC-14) were utilized, in a $3 \times 3 \times 2$ factorial design in three randomized blocks. The seeds were treated with the commercial inoculant at the rate of $8 \mathrm{~g}$ per $\mathrm{kg}$ of seeds. At flowering, plants were sampled to evaluate nodulation and leaves were sampled for macronutrient analysis. At maturity, plants were harvested and seeds weighed. Results showed 
that inoculation of the seeds did not provide the amount of nitrogen required to maximize soybean production. Nitrogen fertilization reduced the nodules but increased nitrogen concentration in the seeds and the yield everywhere. At Mococa, Ribeirão Preto and Votuporanga the cultivar IAC-8 showed greater quantity of dry matter of nodules and nodule number than IAC-14, decreasing the nodule number as the quantity of nitrogen was increased. Only in the third year, at Mococa, the dry matter of nodules of IAC-14 was greater than that of IAC-8. The cultivar IAC-14 produced higher yields than IAC-8 at all three localities and the concentration of nitrogen in the seeds increased with the rates of nitrogen applied. Application of potassium improved nodulation and the concentration of the nitrogen. At Mococa and Votuporanga, potassium aplication increased the yield of soybeans only in the third year, IAC-14 always produced higher yield.

Key words: soybeans; inoculation; rhizobium; fertilization; yield.

\section{INTRODUÇÃO}

Embora fácil de ser cultivada, a soja apresenta como um dos maiores obstáculos para a sua expansão, em regiões tropicais e subtropicais, a escassez de sementes de boa qualidade devido ao baixo poder de armazenamento (Henning e França, 1993). O avanço de áreas irrigadas tem possibilitado o cultivo da soja no outono-inverno para produção de sementes em locais onde a temperatura é amena (Yorinori et al., 1993). A produtividade da estação outono-inverno é menor que a do verão mas, como se destina à produção de sementes e seu preço é superior em $40 \%$ ao da soja industrial, este cultivo tem-se tornado econômico. Os fatores climáticos dessa época são limitantes às pragas, o que reduz o investimento com inseticida. Entretanto, cultivo nessa ocasião exige tratamento de semente por favorecer a sobrevivência de alguns fungos e de nematóides de galha (Yorinori et al., 1993).

A cultura da soja é exigente em nitrogênio, principalmente no 
estádio reprodutivo. No verão, a simbiose rizóbio-leguminosa é eficiente e pode maximizar a produção desde que nenhum fator ambiente ou prática cultural limite a nodulação e a fixação simbiótica. No inverno, Tanaka \& Mascarenhas (1992) observaram que a simbiose não era capaz de suprir adequadamente a demanda por nitrogênio. A ineficiência das estirpes de rizóbio se deve a menor disponibilidade de fotossintetizados em decorrência da baixa temperatura (Buiss et al., 1988). Com o resfriamento do ar, ocorre bloqueio da translocação de assimilados, reduzindo a fixação simbiótica do nitrogênio.

Na região Mogiana do Estado de São Paulo, o cultivo de inverno tem sido feito com pivô central e aplicação de adubo nitrogenado, causando intenso crescimento vegetativo, com acamamento no cultivar IAC-8. Nas áreas onde não se aplicava nitrogênio, o sistema radicular desenvolvia-se apenas superficialmente, causando deficiência do elemento.

Sfredo et al. (1986) relataram que o segundo elemento mais exigido pela soja é o potássio. Devido a expressiva quantidade de potássio exportada pelos grãos, recomenda-se que o nutriente seja reposto no solo pelo menos para restituir o retirado na colheita.

Há relação direta entre a adubação potássica e a qualidade das sementes de soja (Krzyzanowski et al., 1993); está entre os principais benefícios a redução da deiscência das vagens, a uniformização da maturação das plantas, o aumento na germinação e do peso de cem sementes, e a redução drástica no nível de Phomopsis sp (Mascarenhas, 1988 e 1989).

Os objetivos deste experimento foram:

1) verificar se há resposta dos cultivares de soja IAC-8 e IAC-14 inoculados com rizóbio à aplicação de nitrogênio mineral e potássio;

2) verificar se a nodulação, no inverno, é capaz de suprir a demanda por N. 


\section{MATERIAL E MÉTODOS}

O experimento foi instalado nos outonos de 1991, 1992 e 1993, 1as Estações Experimentais do Instituto Agronômico localizadas em Mococa, Ribeirão Preto e Votuporanga, SP. Os solos das três localidades possuem características químicas e físicas distintas conforme mostram os dados da Tabela 1.

Tabela 1. Caracterização da fertilidade e classificação dos solos da camada superficial $(0-20 \mathrm{~cm})$ nas áreas experimentais nos três anos de condução do experimento.

\begin{tabular}{|c|c|c|c|c|c|c|c|c|c|c|}
\hline & $\mathrm{P}$ & M.O. & $\mathrm{pH}$ & $\mathrm{K}$ & $\mathrm{Ca}$ & $\mathrm{Mg}$ & $\mathrm{H}+\mathrm{Al}$ & $\mathrm{S}$ & $\mathrm{T}$ & V \\
\hline & \multicolumn{10}{|c|}{ MOCOCA Argilossolo Vermelho Eutrófico, A Moderado, Textura Argilosa } \\
\hline $1^{0}$. ano & 43 & 32 & 5,5 & 2,9 & 39 & 11 & 23 & 53 & 75 & 70 \\
\hline $2^{0}$. ano & 25 & 30 & 5,0 & 4,0 & 28 & 8 & 43 & 40 & 83 & 48 \\
\hline $3^{0}$. ano & 24 & 26 & 5,0 & 2,5 & 27 & 10 & 34 & 40 & 74 & 54 \\
\hline \multicolumn{11}{|c|}{ RIBEIRÃO PRETO Latossolo Roxo Distrófico } \\
\hline $1^{0}$. ano & 72 & 46 & 6,6 & 4,1 & 97 & 53 & 20 & 154 & 174 & 89 \\
\hline $2^{0}$. ano & 25 & 35 & 5,0 & 5,8 & 31 & 12 & 47 & 49 & 96 & 51 \\
\hline $3^{0}$. ano & 44 & 53 & 5,7 & 3,1 & 41 & 20 & 28 & 64 & 92 & 70 \\
\hline \multicolumn{11}{|c|}{ VOTUPORANGA - Latossolo Vermelho Eutrófico, A Moderado, Textura Média } \\
\hline $1^{0}$. ano & 53 & 19 & 5,8 & 2,4 & 28 & 9 & 14 & 39 & 53 & 74 \\
\hline $2^{0}$. ano & 21 & 16 & 5,4 & 1,4 & 20 & 8 & 15 & 29 & 44 & 66 \\
\hline $3^{0}$. ano & 23 & 11 & 5,7 & 2,3 & 24 & 12 & 15 & 38 & 53 & 72 \\
\hline
\end{tabular}

Para o preparo do solo utilizou-se o sistema convencional, com aração e gradagem. Doses de nitrogênio na forma de uréia $(0,50$ e 100 $\left.\mathrm{kg} \cdot \mathrm{ha}^{-1}\right)$, de $\mathrm{K}_{2} 0$ na forma de cloreto de potássio $\left(0,30\right.$ e $\left.60 \mathrm{~kg} \cdot \mathrm{ha}^{-1}\right)$ e dois 
cultivares de soja (IAC-8 e IAC-14) foram combinados em fatorial de $3 \times 3 \times 2$ e dispostas no campo em três blocos ao acaso. Um terço das doses dos dois nutrientes foi aplicado em cobertura e em faixas, dez dias após a emergência da soja, e o restante, depois de vinte dias. Para evitar perdas dos adubos por volatilização, logo após a aplicação, foram eles recobertos com solo. Foram distribuídas 30 sementes, por metro linear, inoculadas com inoculante turfoso comercial na dose de 8 g. $\mathrm{kg}^{-1}$. As estirpes de Bradyrhizobium japonicum empregadas foram SEMIA-587 e SEMIA-5019 (=w-29).

As parcelas eram compostas por quatro linhas de seis metros, espaçadas de $0,60 \mathrm{~m}$. Nas linhas centrais, descontando-se $0,50 \mathrm{~m}$ em cada extremidade, foram realizadas as avaliações de produção de grãos, e as laterais sorteadas para amostragem de nodulação e coleta de material para determinação do teor de nitrogênio acumulado.

As datas da semeadura, emergência, florescimento, amostragem e colheita são apresentadas na Tabela 2.

O experimento foi irrigado por aspersão sempre que apareceram sintomas iniciais de deficiência hídrica nas plantas. As amostragens foram realizadas nos três locais, na época do florescimento pleno das plantas, ou seja, no estádio $R_{5}$ segundo Hanway \& Thompson (1971), sendo coletadas três plantas por parcela dentro da linha sorteada para as determinações de massa seca e número de nódulos e o teor de $\mathrm{N}$ acumulado na parte aérea. Após a colheita, os grãos foram moídos em moinho tipo Wiley e determinados os teores de nitrogênio e de potássio pelo método descrito por Bataglia et al. (1978).

O efeito dos tratamentos foi verificado pela análise de variância (Tabela 3). Para a análise dos efeitos de doses de nitrogênio e de $\mathrm{K}_{2} \mathrm{O}$ foi usada regressão polinomial. Não foi realizada análise conjunta para locais e anos pois os dados mostraram ser heterogêneos pelo teste de Hartley para algumas variáveis (Nogueira, 1991). 
Tabela 2. Datas de semeadura, emergência, florescimento e colheita dos cultivares IAC-8 e IAC-14 e número de dias necessários para completar cada estádio de desenvolvimento em Mococa, Ribeirão Preto e Votuporanga, SP, em 1991, 1992 e 1993.

\begin{tabular}{|c|c|c|c|c|c|c|}
\hline \multirow{3}{*}{$\begin{array}{l}\text { Estádio de } \\
\text { Crescimento }\end{array}$} & \multicolumn{6}{|c|}{ Mococa } \\
\hline & \multicolumn{2}{|c|}{1991} & \multicolumn{2}{|c|}{1992} & \multicolumn{2}{|c|}{1993} \\
\hline & Datas & $\mathrm{N}^{\circ}$. de Dias & Datas & $\mathrm{N}^{0}$. de Dias & Datas & $\mathrm{N}^{0}$. de Dias \\
\hline Semeadura & $29-05-91$ & - & $18-05-92$ & - & $24-05-93$ & - \\
\hline Germinação & $10-06-91$ & 12 & $28-05-92$ & 10 & $31-05-93$ & 7 \\
\hline Florescimento & $09-08-91$ & 60 & $22-07-92$ & 54 & $31-08-93$ & 61 \\
\hline Colheita & $08-11-91$ & 91 & $29-09-92$ & 70 & $11-10-93$ & 72 \\
\hline Ciclo Total & - & 153 & - & 134 & - & 140 \\
\hline Estádio de & \multicolumn{6}{|c|}{ Ribeirão Preto } \\
\hline \multirow[t]{2}{*}{ Crescimento } & \multicolumn{2}{|c|}{1991} & \multicolumn{2}{|c|}{1992} & \multicolumn{2}{|c|}{1993} \\
\hline & Datas & $\mathrm{N}^{\circ}$. de Dias & Datas & $\mathrm{N}^{\circ}$. de Dias & Datas & $N^{\circ}$. de Dias \\
\hline Semeadura & $06-06-91$ & - & $08-05-92$ & - & $25-05-93$ & - \\
\hline Germinação & $17-06-91$ & 11 & $17-05-92$ & 9 & $05-06-93$ & 11 \\
\hline Florescimento & $12-08-91$ & 56 & $06-07-92$ & 50 & $05-07-93$ & 29 \\
\hline Colheita & $01-11-91$ & 81 & $15-09-92$ & 71 & $19-10-93$ & 106 \\
\hline Ciclo Total & - & 148 & - & 130 & - & 147 \\
\hline Estádio de & \multicolumn{6}{|c|}{ Votuporanga } \\
\hline \multirow[t]{2}{*}{ Crescimento } & \multicolumn{2}{|c|}{1991} & \multicolumn{2}{|c|}{1992} & \multicolumn{2}{|c|}{1993} \\
\hline & Datas & $\mathrm{N}^{\circ}$. de Dias & Datas & $\mathrm{N}^{\circ}$. de Dias & Datas & $\mathrm{N}^{\circ}$. de Dias \\
\hline Semeadura & $18-06-91$ & - & $05-06-92$ & - & $21-05-93$ & - \\
\hline Germinação & $26-06-91$ & 8 & $11-06-92$ & 6 & $29-05-93$ & 8 \\
\hline Florescimento & $16-08-91$ & 51 & $04-08-92$ & 54 & $11-08-93$ & 43 \\
\hline Colheita & $24-10-91$ & 69 & $16-10-92$ & 73 & $28-10-93$ & 48 \\
\hline Ciclo Total & - & 138 & - & 133 & - & 120 \\
\hline
\end{tabular}


Tabela 3. Esquema da análise de variância empregada para as diferentes variáveis analisadas.

\begin{tabular}{lc}
\hline Causa de Variação & Graus de Liberdade \\
\hline Cultivares & 1 \\
Doses de Nitrogênio & 2 \\
Doses de Potássio & 2 \\
Interação Cultivares x Doses de Nitrogênio & 2 \\
Interação Cultivares x Doses de Potássio & 2 \\
Residuo & 44 \\
\hline Total & 53 \\
\hline
\end{tabular}

\section{RESULTADOS E DISCUSSÃO}

Para um mesmo cultivar de soja, houve diferenças entre os locais avaliados quanto ao número de dias necessários para que suas plantas emergissem, florescessem e atingissem a maturidade (Tabela 2) o que também foi observado por Barron et al. (1999) em linhagens de feijoeiro. Em Votuporanga, as temperaturas, sempre mais elevadas que nos outros dois locais, acarretou desenvolvimento mais rápido da soja, diminuindo o número de dias necessários para completar o ciclo. Segundo Camargo (1984), esse fato se deve ao maior acúmulo térmico. Em soja cultivada no outono-inverno, o estresse térmico pode afetar o metabolismo da planta, a fixação simbiótica do nitrogênio e, possivelmente, a produtividade de grãos (Krzynowski et al., 1993).

Diferenças entre cultivares: $\mathrm{Na}$ Tabela 4 são apresentadas as diferenças nos parâmetros avaliados dos cultivares IAC-8 e IAC-14, nos anos de 1991 a 1993, em Mococa , Ribeirão Preto e Votuporanga. Observou-se em Mococa, em 1992, que o IAC-8 apresentou maior número, massa seca de nódulos e acúmulo de N no grão que o IAC-14. Entretanto, nesse mesmo ano e local, a produção de grãos foi maior no IAC-14: $221 \mathrm{~kg} \cdot \mathrm{ha}^{-1}$ a mais que o IAC-8. Em 1991, em Mococa, o IAC-14 também foi mais produtivo. 


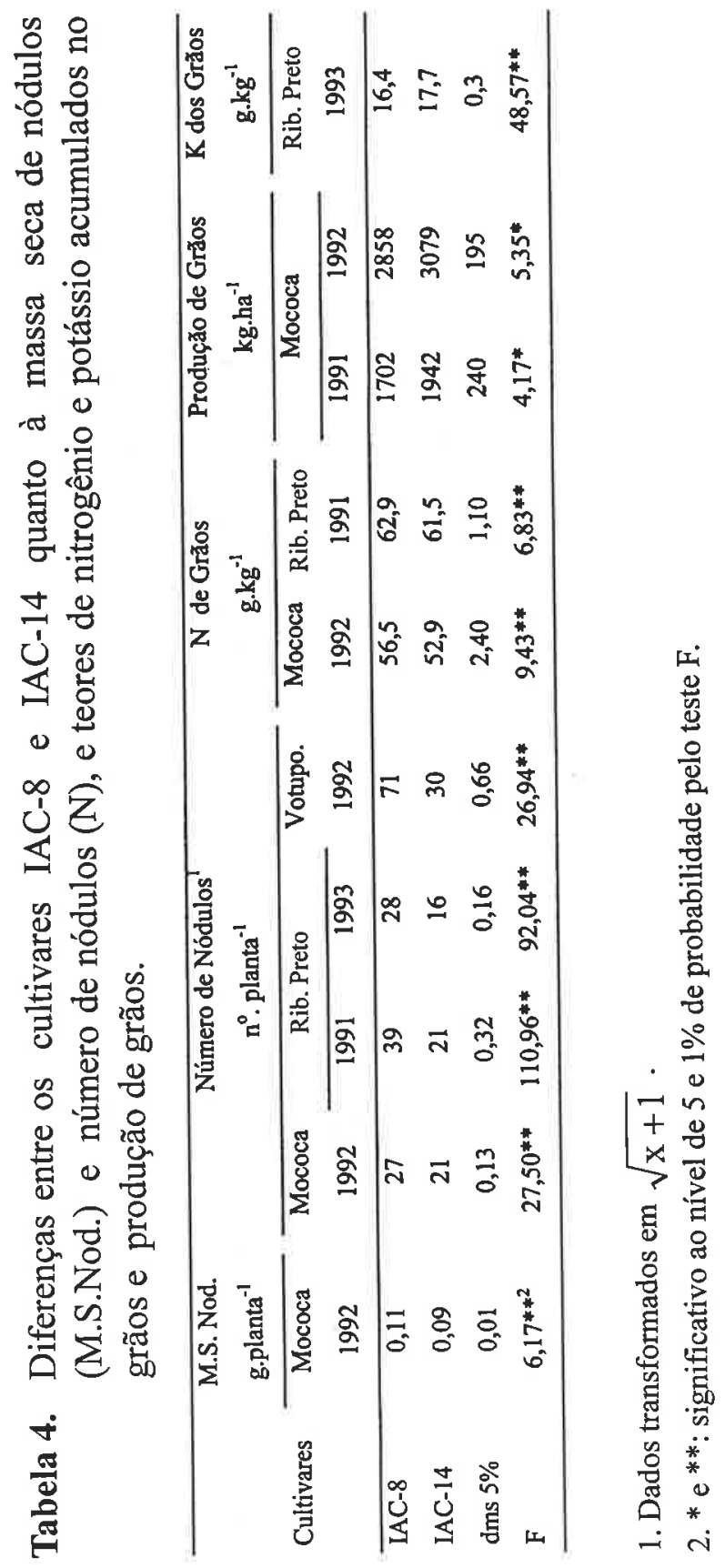


Nos experimentos de Ribeirão Preto, em 1991 e 1993, e de Votuporanga, em 1992, o número de nódulos foi maior no IAC-8. Este cultivar apresentou também maior teor de $\mathrm{N}$ acumulado nos grãos, em 1991, no experimento de Ribeirão Preto. Entretanto, neste mesmo local, em 1993, o teor de potássio acumulado nos grãos foi maior no IAC-14.

É bastante conhecida a variabilidade genética entre cultivares nas espécies de leguminosas quanto ao estabelecimento da simbiose com rizóbio. Segundo Andriolo et al. (1994), em feijoeiro, esta variabilidade reflete-se em diferenças na massa, número e eficiência dos nódulos e no N total acumulado. Vasillas \& Fuhrmann (1993) observaram que existe associação entre produção de grãos de soja e acúmulo de $\mathrm{N}$ na planta, sugerindo que a produção possa ser aumentada quando a nodulação for devida a estirpes melhoradas de B. japonicum. No presente caso, essa associação não foi observada. Herridge \& Rose (2000) também observaram que os fatores genéticos da planta influenciam a nodulação e a fixação; entretanto, se a população é inadequada ou ineficiente, a simbiose pode ser reduzida, o que pode causar diminuição na produção. Além disso, as estirpes de rizóbio introduzidas nem sempre competem com sucesso com as autóctones por sítios de infecção. Segundo Vasillas \& Fuhrmann (1993), menos de $10 \%$ dos nódulos formados são devidos ao rizóbio proveniente da inoculação.

Efeito da aplicação de nitrogênio: O efeito da aplicação de nitrogênio nos três anos de experimentação é apresentado na Figura 1. Em 1992 e 1993, respectivamente para Mococa e Ribeirão Preto, o número e a massa nodular foram linear e inversamente correlacionados com a dose de nitrogênio aplicada (Figuras 1a e 1b). O mesmo foi observado para número de nódulos em 1993 em Votuporanga. No experimento de Ribeirão Preto, em 1991, o número de nódulos ajustou-se de acordo com uma equação do segundo grau onde diminuições foram observadas até a dose aproximada de $88 \mathrm{~kg} \cdot \mathrm{ha}^{-1}$ de N. A partir desta dose, houve aumento no número de nódulos atingindo, com a adição de $100 \mathrm{~kg}$.ha- ${ }^{-1}$ o mesmo valor obtido no tratamento sem $\mathrm{N}$ (Figura 1b). Nos tratamentos com a 
aplicação de $100 \mathrm{~kg} \cdot \mathrm{ha}^{-1}$ de N, embora houvesse grande número de nódulos, os interiores deles estavam brancos, mostrando não estar havendo fixação simbiótica. Giller \& Wilson (1991) observaram que o efeito do N sobre a nodulação pode ser manifestado no desenvolvimento dos nódulos; a massa por planta, é reduzida enquanto que o número total permanece inalterado.

Chen et al. (1992) também observaram diminuição linear no número, massa e tamanho de nódulos com adição de N. Vários autores demonstraram que há relação inversa entre a aplicação de $\mathrm{N}$ mineral, nodulação e fixação simbiótica do nitrogênio em soja. Vernetti (1983) relatou que quando o $\mathrm{N}$ é absorvido do solo ou de fertilizante incorporado, a planta utiliza certa quantidade de assimilado que antes ficava disponível ao nódulo, para crescer e para sintetizar proteína. Essa redução de fotoassimilado resulta em decréscimo na fixação do $\mathrm{N}$.

Em 1991, nos três locais, o teor de $\mathrm{N}$ acumulado na parte aérea aumentou com a adição de N. O mesmo foi observado em Votuporanga em 1992 (Figura 1c). Em Mococa, em 1991 e 1992, foi observado aumento linear no nitrogênio acumulado no grão com a adição de N (Figura 1d). Entretanto, em Mococa, em 1993, o acúmulo de K no grão foi linearmente reduzido com a aplicação de $\mathrm{N}$ (Figura 1e).

Em Mococa nos três anos, e em Ribeirão Preto e Votuporanga em 1991, a produtividade de grãos foi incrementada pela adição de nitrogênio (Figura 1f). De acordo com Ohlrodge (1960), o rendimento de grãos de soja está intimamente correlacionado com a quantidade de $\mathrm{N}$ acumulado pela planta durante seu ciclo. Observando-se as doses de nitrogênio nas quais se obtiveram os maiores teores de $\mathrm{N}$ acumulado na parte aérea, verificou-se que estes estão próximos daqueles em que se obteve produção máxima. Tanaka (1985) verificou que a adição de adubo nitrogenado aumentaria a disponibilidade desse elemento e, sendo absorvido pelas plantas, causariam maior acúmulo de $\mathrm{N}$ nos grãos com reflexos na produção. Este aumento expressivo obtido no rendimento de grãos com o aumento da dose de nitrogênio indica que, no inverno, para maximizar a produção é conveniente fazer adubação nitrogenada. 

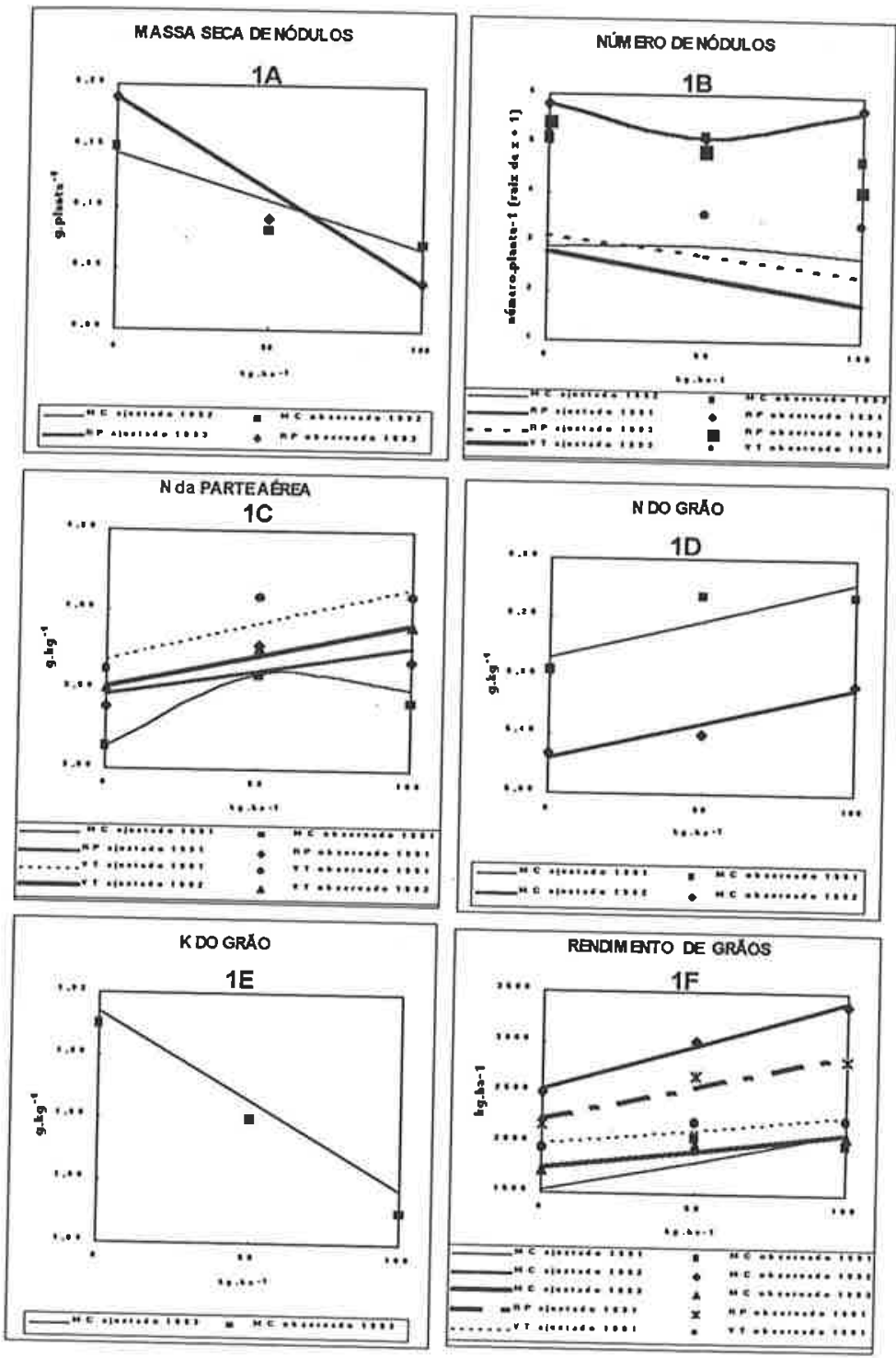

Figura 1. Efeito da aplicação de doses de nitrogênio na quantidade de massa seca e no número de nódulos, no teor de nitrogênio acumulado na parte aérea e nos grãos, no teor de potássio acumulado no grão e na produção de grãos. 


\section{Efeito da interação entre cultivares e doses de nitrogênio: Em} 1991 e 1993, em Mococa, a nodulação dos dois cultivares foi prejudicada pela adição de nitrogênio ao solo (Tabela 5). Segundo Vargas et al. (1993), o grâu de inibição é dependente da dose aplicada sendo mais acentuado quando o nitrogênio é colocado no sulco de semeadura. Observou-se também que a massa nodular de ambos os cultivares, nas diferentes doses de nitrogênio, foi muito menor em 1991 que em 1993. Esse fato pode ter sido devido ao clima pois em 1991 houve estresse térmico. Siqueira \& Franco (1988) verificaram que a simbiose leguminosa-rizóbio é sensível aos extremos de temperatura, que afeta tanto o processo de infeç̧ão como o desenvolvimento dos nódulos. Entretanto, várias pesquisas demonstraram que sob baixa temperatura, o processo de infecção pode ocorrer mas há menor desenvolvimento do nódulo, o que deixa menor a massa nodular. O IAC-14 apresentou menor massa e número de nódulos em 1991 que em 1993 concordando com o observado por Sinclair et al. (1991) que relataram haver variação nas características da nodulação da soja entre cultivares de soja devido a fatores ambientais.

Em 1992, em Mococa, foi observado aumento linear no teor de nitrogênio acumulado na parte aérea em ambos os cultivares, com o aumento da dose de nitrogênio aplicado (Tabela 5). O mesmo ocorreu em 1993, mas atingiu um máximo com as doses estimadas de 64 e 38 kg.ha- ${ }^{-1}$ de N, respectivamente, para IAC-8 e IAC-14. Em relação ao teor de nitrogênio acumulado nos grãos, verificou-se que, em 1993, em Mococa, para ambos os cultivares, houve efeito linear positivo com o aumento da dose de $\mathrm{N}$ aplicada o que já havia sido relatado por Hanway \& Weber (1971).

Em relação à interação entre cultivares e doses de nitrogênio, em Ribeirão Preto, em 1991 e 1992, verificou-se que a massa nodular foi reduzida com a aplicação de $\mathrm{N}$, assim como o número de nódulos em 1992 (Tabela 6). No cultivar IAC-8, com a aplicação de qualquer das doses de $\mathrm{N}$, o número de nódulos foi maior que no IAC-14. Inexplicavelmente, em 1992, o teor de $\mathrm{N}$ acumulado na parte aérea do IAC-8 diminuiu linearmente com a adição de N. Entretanto, em 1993, o 


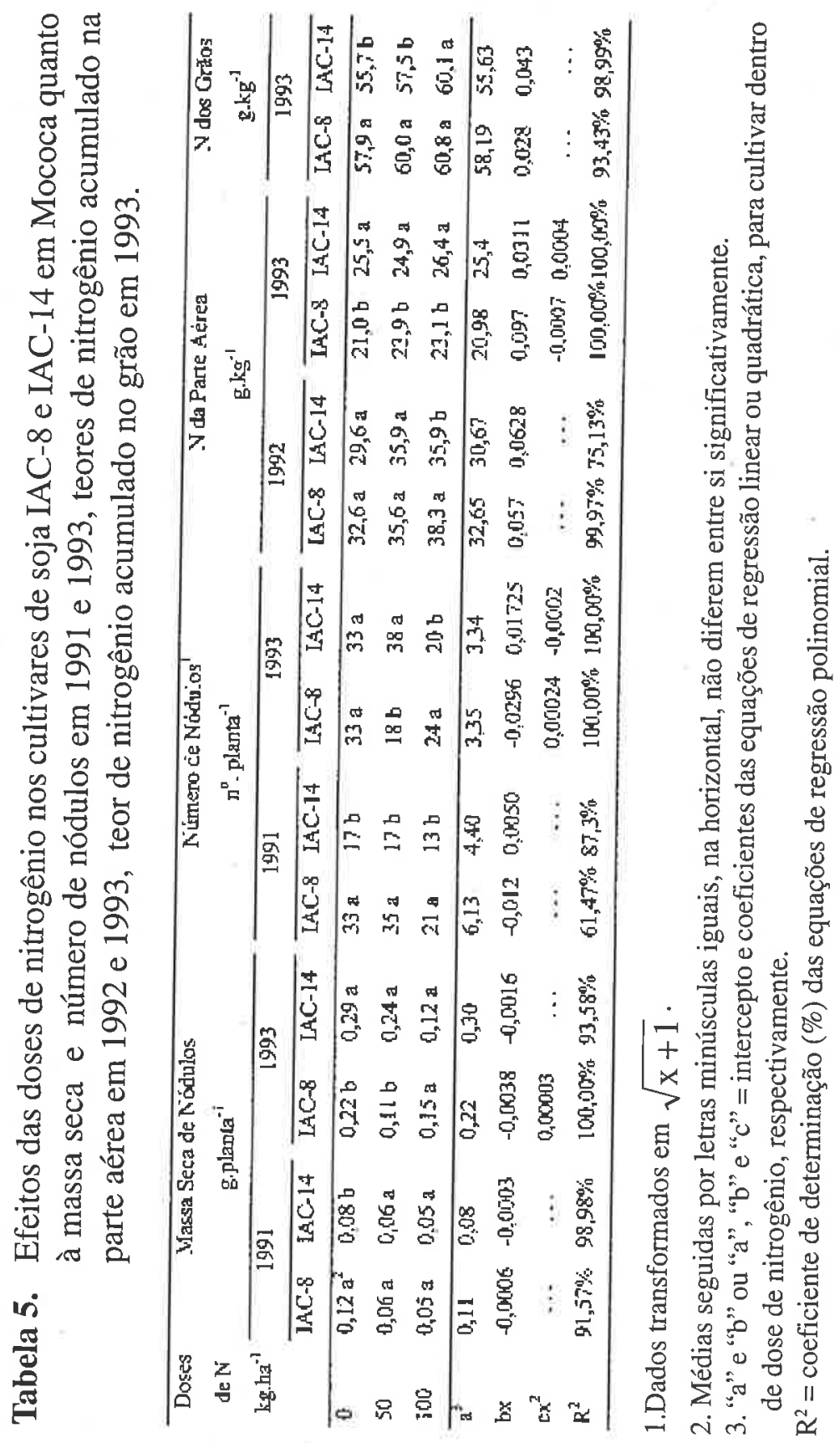


ıúmulo de $\mathrm{N}$ da parte aérea e de grãos e a produção de grãos aumenraram em ambos os cultivares com o incremento da doses aplicadas. $\mathrm{O}$ teor de potássio dos grãos, em 1992, aumentou linearmente apenas no [AC-14

Em Votuporanga, nos três anos, para ambos os cultivares, a massa nodular foi linearmente reduzida com o aumento da dose de $\mathrm{N}$ aplicada (Tabela 7). Em 1992 e 1993, verificou-se que o IAC-8 apresentou maior massa nodular que o IAC-14 até a aplicação de $50 \mathrm{~kg} \cdot \mathrm{ha}^{-1}$ de N. O número de nódulos, em 1991, foi maior no IAC-8 mas em ambos houve redução linear com o aumento da dose de $\mathrm{N}$ aplicado. Os acúmulos de $\mathrm{N}$ da parte aérea e no grão e a produção de grãos foram beneficiados pela adição de N (Tabela 8). Quando foi aplicado N, o cultivar IAC14, em 1993, apresentou maior acúmulo de $\mathrm{N}$ nos grãos que o IAC-8 ocorrendo o oposto quando avaliou-se a produção de grãos. Mascarenhas et al. (1980) também observaram que cada cultivar de soja tem exigência nutricional própria. Yinbo et al. (1997) observaram que a adição de $\mathrm{N}$ em cobertura aumentava a produção de soja e que a época de aplicação tem papel importante. Recomendam que a aplicação seja feita antes do estádio reprodutivo, pois assim favorece o crescimento da planta, aumenta a área foliar, resultando abundante florescimento e maior produção.

Efeito da aplicação de potássio: Pelos dados da Figura 2 (a e b), verificou-se que, em 1992, em Mococa, a nodulação diminuiu atingindo valor mínimo nas doses entre $20 \mathrm{e} 30 \mathrm{~kg}$.ha-1 $\mathrm{de}_{2} \mathrm{O}$. A partir desta dose, a nodulação voltou a crescer, atingindo, com a aplicação de $60 \mathrm{~kg} \cdot \mathrm{ha}^{-1}$, valores próximos aos obtidos sem a adição deste nutriente. Franco \& Dobereiner (1967) observaram que a massa e o número de nódulos eram maiores em áreas onde não havia sido aplicado potássio. Stamford et al. (1980) também verificaram efeito depressivo do potássio no número de nódulos, relatando que o nível deste elemento deve ser baixo para que haja formação de nódulo.

Em 1993, em Votuporanga, a massa nodular aumentou até a adição de $30,5 \mathrm{~kg}$ ha ${ }^{-1}$ de $\mathrm{K}_{2} \mathrm{O}$, voltando, a partir desta dose, a apresentar os mesmos valores do tratamento testemunha (Figura $2 \mathrm{a}$ ). Os teores de po- 


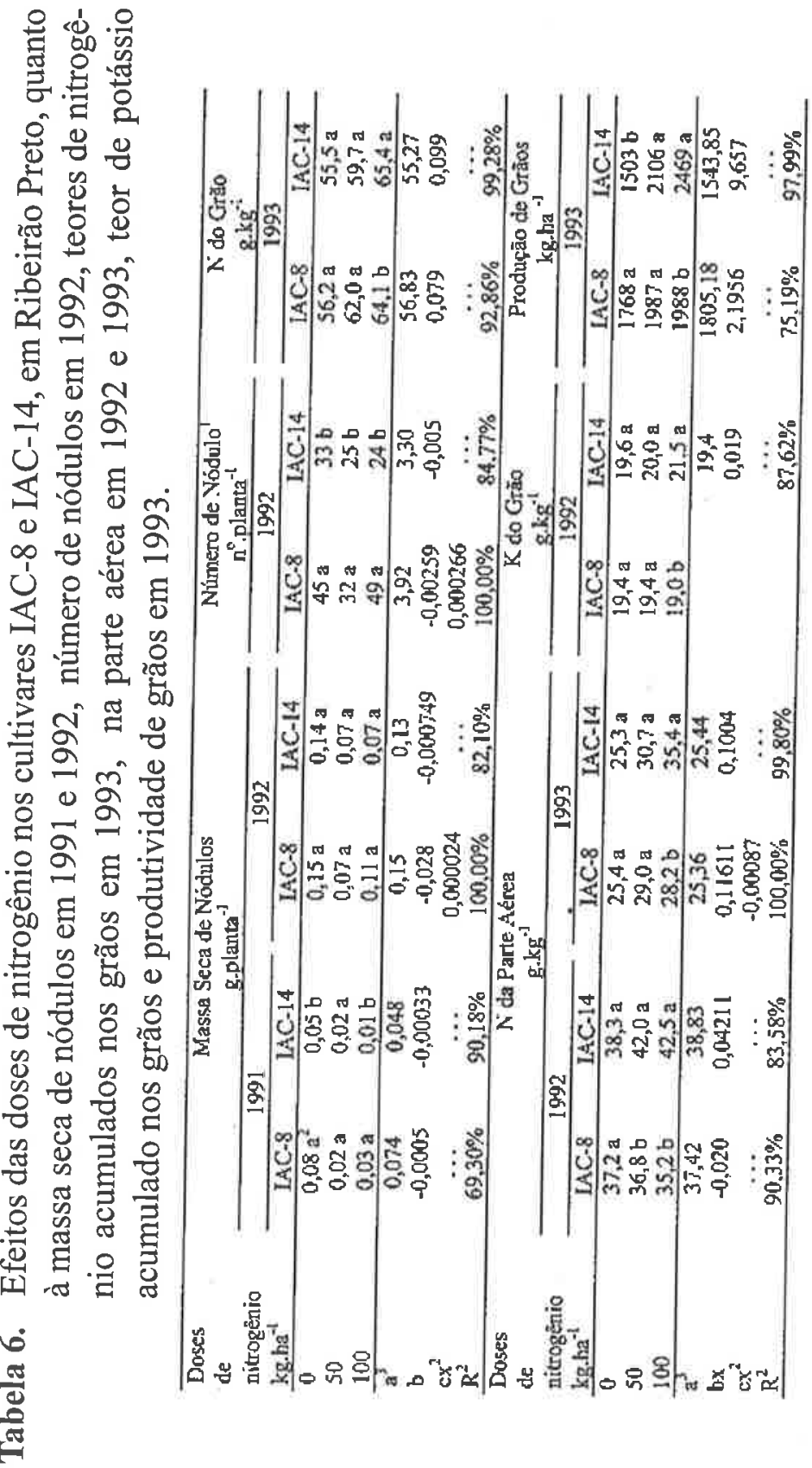

옹

疍

苟

总

in

논

苞荡

윰

낭

馬焉

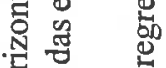

통

व

政

.

氙 छ

氙 宫

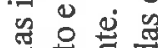

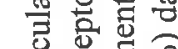

十色兔震

凶苜志总

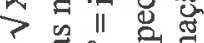

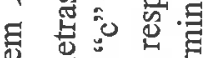

\%

응

光

E.

龸

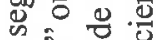

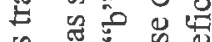

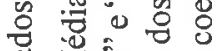

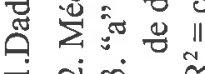


Tabela 7. Efeitos das doses de nitrogênio nos cultivares de soja IAC-8 e IAC-14, em Votuporanga, quanto à massa seca de nódulos em 1991, 1992 e 1993 e no número de nódulos em 1991.

\begin{tabular}{|c|c|c|c|c|c|c|c|c|}
\hline \multirow{3}{*}{$\begin{array}{l}\text { Dosés } \\
\text { de } \\
\text { nitrogênio } \\
\mathrm{kg} \mathrm{ha}^{-1}\end{array}$} & \multicolumn{6}{|c|}{$\begin{array}{c}\text { Massa Seca de Nódulos } \\
\text { g.planta }\end{array}$} & \multirow{2}{*}{\multicolumn{2}{|c|}{$\begin{array}{c}\begin{array}{c}N^{0} \text {. de Nódulos } \\
n^{1} \cdot \text { planta }^{-1}\end{array} \\
1991\end{array}$}} \\
\hline & \multicolumn{2}{|c|}{1991} & \multicolumn{2}{|c|}{1992} & \multicolumn{2}{|c|}{1993} & & \\
\hline & IAC-8 & IAC-14 & IAC-8 & IAC-14 & IAC-8 & IAC-14 & IAC-8 & IAC-14 \\
\hline 0 & $0,09 \mathrm{a}^{2}$ & $0,06 \mathrm{a}$ & $0,27 \mathrm{a}$ & $0,21 \mathrm{~b}$ & $0,33 \mathrm{a}$ & $0,23 \mathrm{~b}$ & $34 \mathrm{a}$ & $13 \mathrm{~b}$ \\
\hline 50 & $0,02 \mathrm{a}$ & $0,02 \mathrm{a}$ & $0,27 \mathrm{a}$ & $0,19 \mathrm{~b}$ & $0,13 \mathrm{a}$ & $0,06 \mathrm{~b}$ & $28 \mathrm{a}$ & $8 \mathrm{~b}$ \\
\hline 100 & $0,01 \mathrm{a}$ & $0,00 \mathrm{~b}$ & $0,17 \mathrm{a}$ & $0,16 \mathbf{a}$ & $0,07 \mathrm{a}$ & $0,07 \mathrm{a}$ & $14 \mathrm{a}$ & $4 \mathrm{~b}$ \\
\hline$a^{3}$ & 0,0808 & 0,0605 & 0,2906 & 0,2157 & 0,3103 & 0,2050 & 6,156 & 3,757 \\
\hline$b x$ & $-0,00072$ & $-0,00058$ & $-0,00095$ & $-0,00045$ & $-0,0026$ & $-0,00157$ & $-0,021$ & $-0,0135$ \\
\hline $\mathrm{R}^{2}$ & $79,66 \%$ & $90,200 \%$ & $69,76 \%$ & $99,09 \%$ & $92,10 \%$ & $70,69 \%$ & $92,59 \%$ & $98,96 \%$ \\
\hline
\end{tabular}

1.Dados transformados em $\sqrt{\mathrm{x}+1}$.

2. Médias seguidas por letras minúsculas iguais, na horizontal, não diferem entre si significativamente.

3. "a" e "b" ou "a", "b" e "c" = intercepto e coeficientes das equações de regressão linear ou quadrática, para cultivar dentro de dose de nitrogênio, respectivamente. $\mathrm{R}^{2}=$ coeficiente de determinação (\%) das equações de regressão polinomial.

tássio do solo das três áreas experimentais eram elevados. Provavelmente, o efeito benéfico do potássio ocorrido em Votuporanga seja devido ao tipo de solo. Como a área experimental estava sobre solo arenoso com irrigação, ocorria maior lixiviação do potássio e não havia acúmulo do elemento.

Em Ribeirão Preto, em 1993, o acúmulo de $\mathrm{N}$ e a produção de grãos foram prejudicados pela adição de potássio (Figuras 2c e 2d). Entretanto, em Mococa, nesse mesmo ano, a produção de grãos foi aumentada atingindo o máximo com $30 \mathrm{~kg} \cdot \mathrm{ha}^{-1}$ de $_{2} \mathrm{O}$. Duke \& Collins (1980) relataram que quando o teor de potássio do solo era adequado, se fosse adicionado mais, sua concentração nos tecidos aumentava muito pouco, podendo inclusive diminuir. 


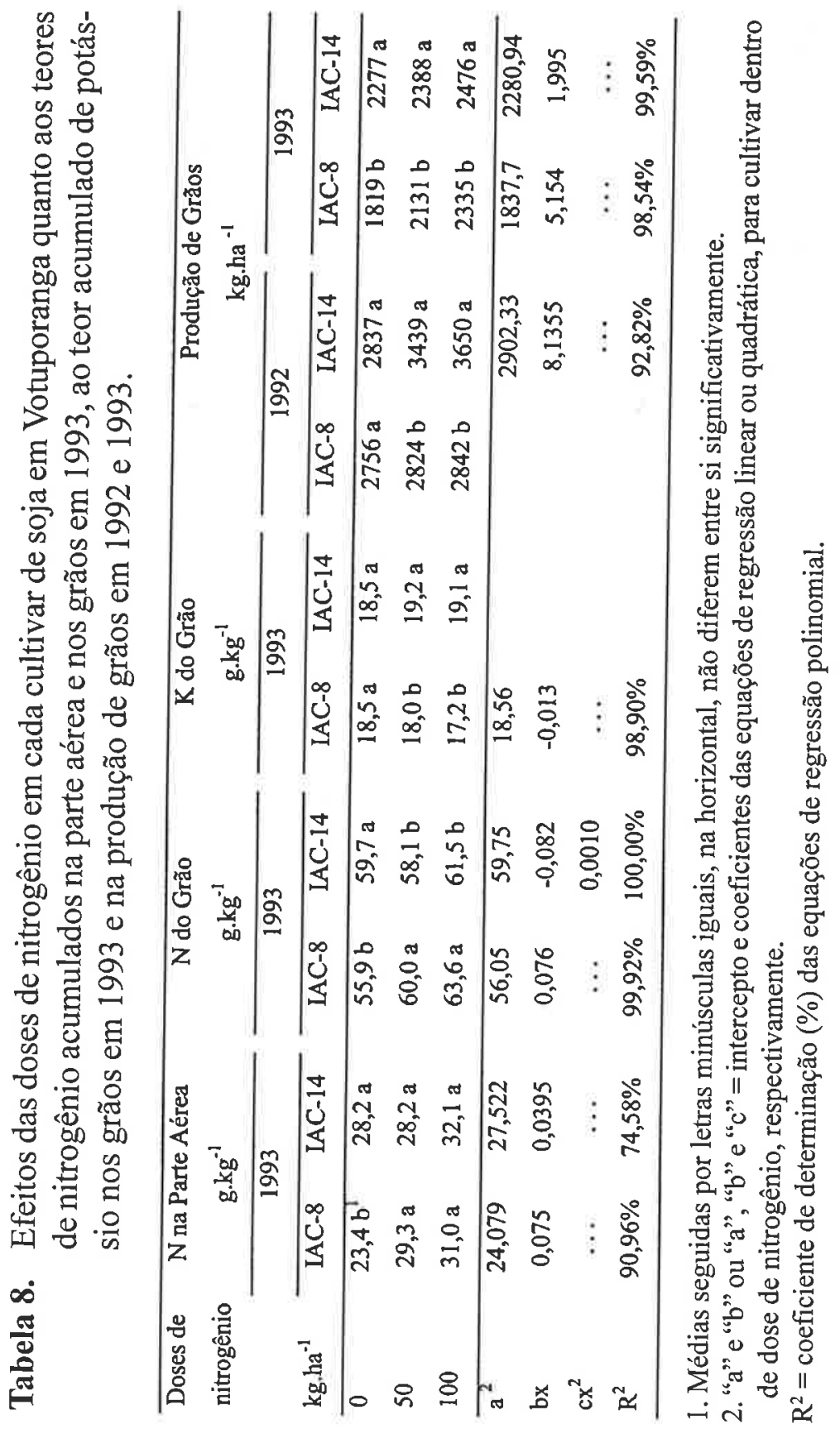



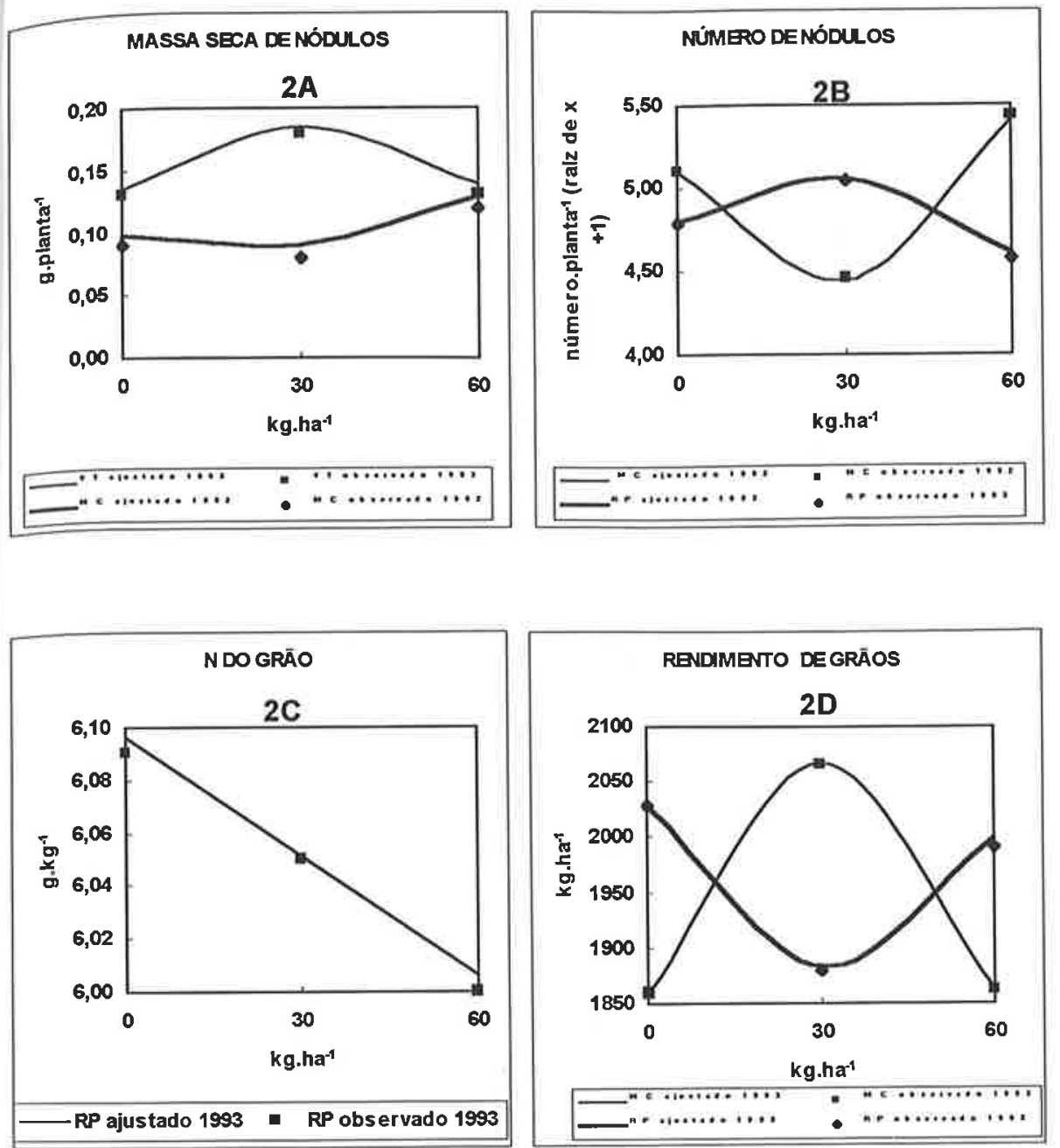

Figura 2. Efeito da aplicação de doses de potássio na quantidade de massa seca e no número de nódulos, no teor de nitrogênio acumulado nos grãos e na produção de grãos.

Efeito da interação entre cultivares e doses de potássio: Os dados relativos à interação entre cultivares e doses de potássio para os três locais são apresentados nos Tabelas 9, 10 e 11. De modo 


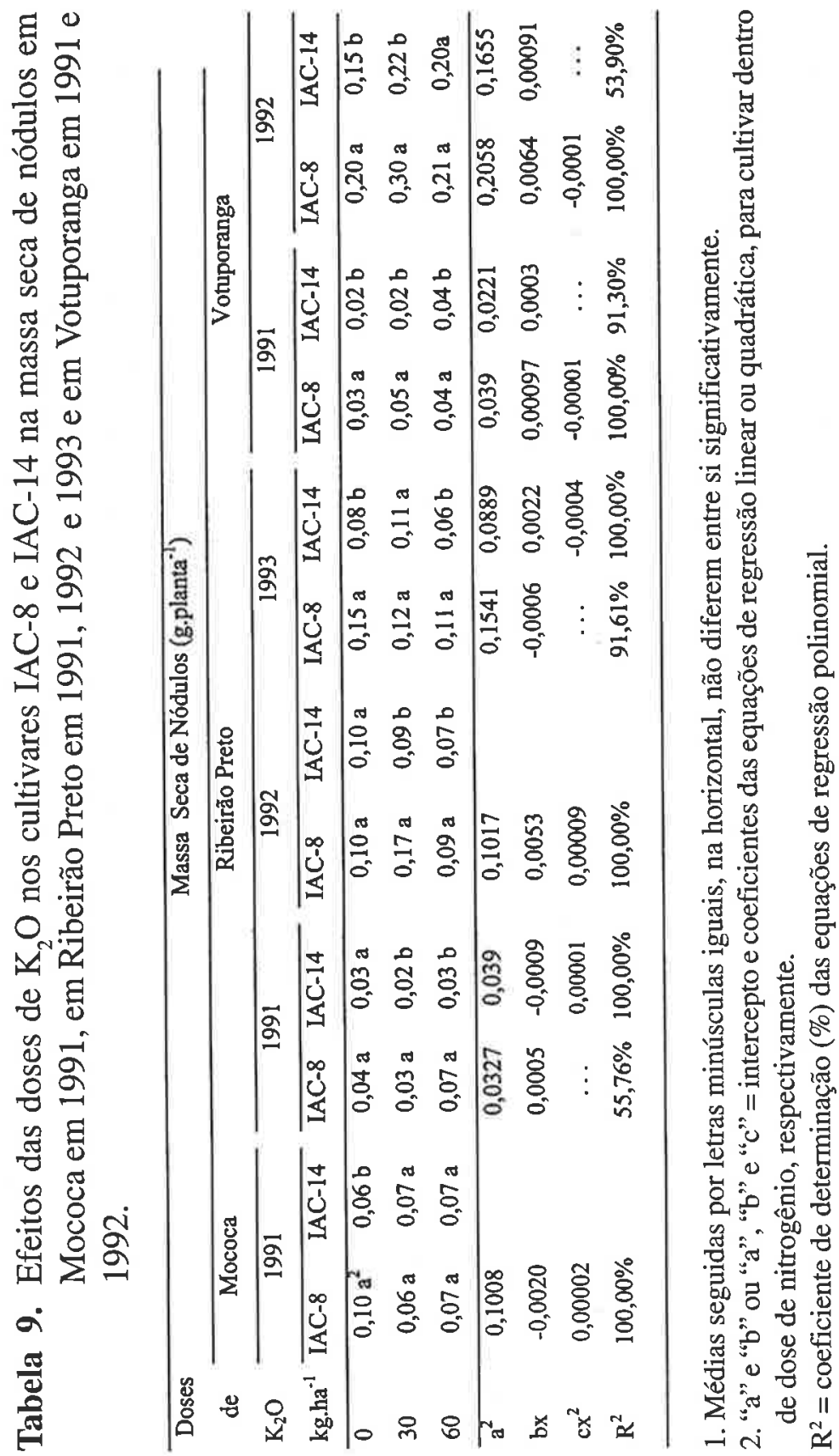




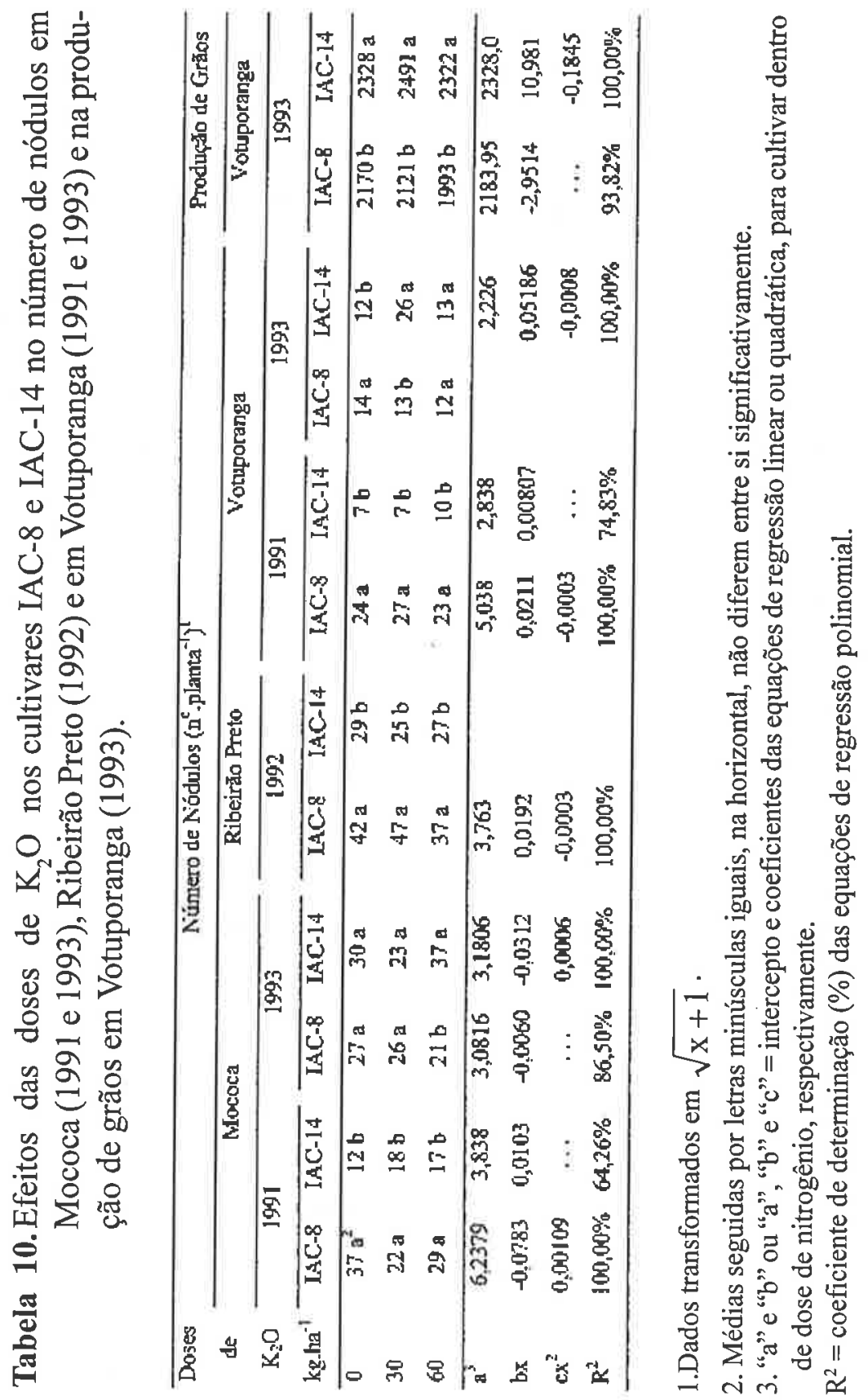


(Tabela 11). A resposta da soja ao acúmulo de nutriente nos grãos ou na parte aérea pode ser limitada pela capacidade fisiológica das raízes como órgãos de absorção de nutrientes. Segundo Raper Jr. \& Barber (1970), uma das possíveis limitações fisiológicas para a absorção de nutrientes é a densidade de locais de absorção. Genótipos de soja com diferentes sistemas radiculares podem apresentar diferenças na taxa de absorção de nutrientes por planta. Foi também observado que a eficiência de absorção de potássio por unidade superficial de raiz depende da variedade e da concentração de potássio da solução.

Em Ribeirão Preto, o comportamento dos cultivares em relação à adição de potássio sobre a massa nodular variou ano a ano. Em 1991 e 1993, no IAC-8, a massa nodular aumentou e diminuiu respectivamente, com a adição de potássio (Tabela 9). Em 1992, para esse mesmo cultivar, observou-se que a resposta se ajustava a uma equação do segundo grau, atingindo o máximo com $27 \mathrm{~kg} \cdot \mathrm{ha}^{-1}$ de $\mathrm{K}_{2} \mathrm{O}$. O IAC-14 teve sua massa nodular diminuída em 1991 e aumentada em 1993 com a aplicação de potássio. Ainda em Ribeirão Preto, em 1992, o número de nódulos do IAC-8 foi superior ao do IAC-14 para quaisquer das doses aplicadas (Tabela 10). No IAC-8, a formação de nódulo foi estimulada pela adição de potássio atingindo valor máximo com a dose estimada de $32 \mathrm{~kg} \cdot \mathrm{ha}^{-1}$ de $\mathrm{K}_{2} \mathrm{O}$.

Em Votuporanga, em 1991, para ambos os cultivares, a nodulação aumentou com a adição de potássio, ocorrendo o mesmo para massa nodular em 1992 (Tabelas 9 e 10). Em 1993, quanto ao número de nódulos, apenas o IAC-14 respondeu positivamente ao potássio (Tabela 10). Em relação ao acúmulo de nitrogênio na parte aérea devido a aplicação de potássio, verificou-se que o IAC-8, em 1992 e 1993, apresentou aumento e diminuição nos seus teores, respectivamente (Tabela 11). O IAC14 apresentou aumento em 1991 e redução em 1993 no teor acumulado na parte aérea. Em 1993, ambos os cultivares apresentaram redução no teor de potássio acumulado nos grãos com a adição de potássio. Em 1991 e 1992, os teores de potássio do solo antes da adubação estavam bem mais baixos que em 1993, o que explica o aumento no acúmulo nos primeiros anos e diminuição no terceiro. 


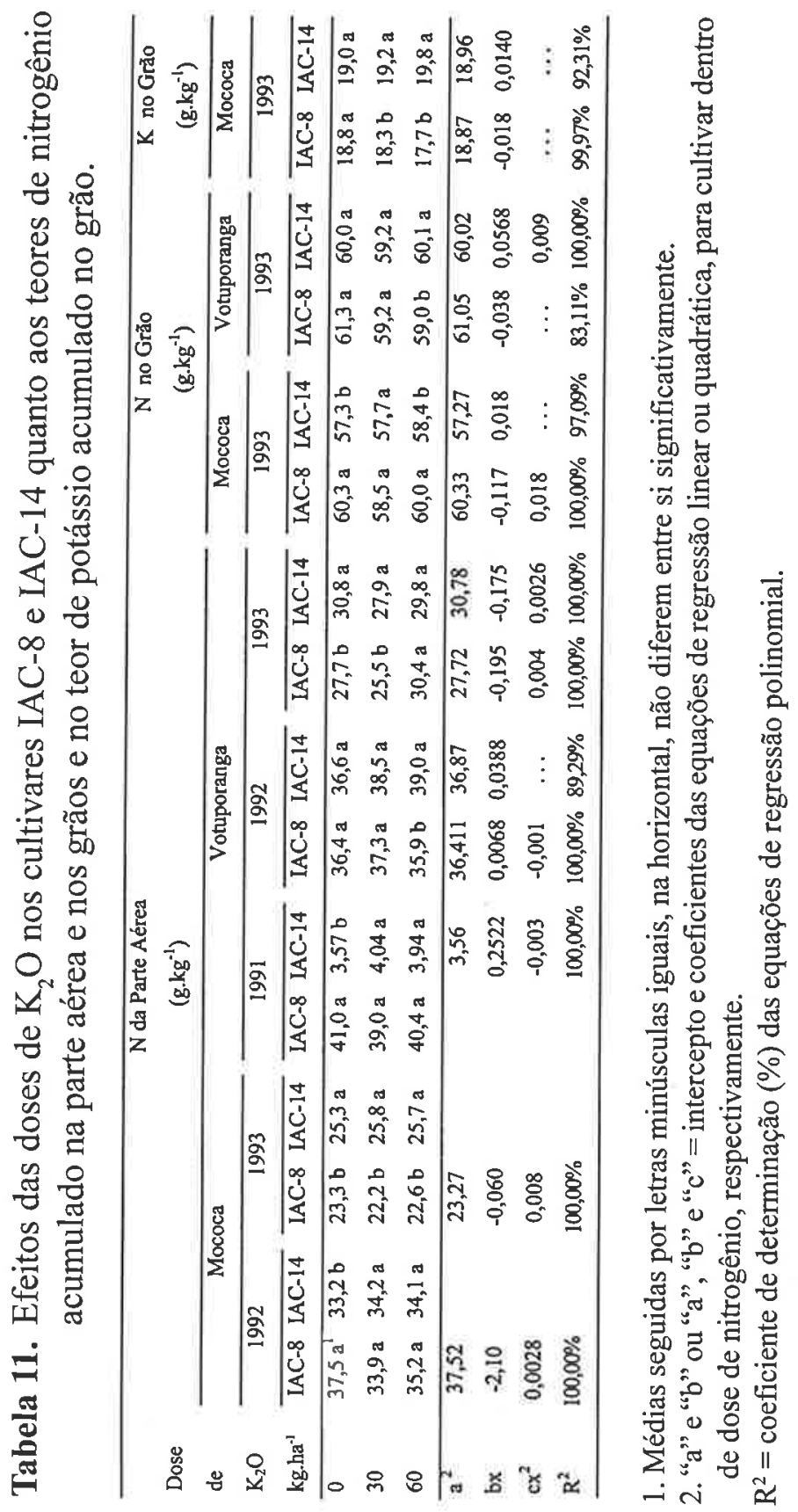


Em Votuporanga, verificou-se que o cultivar IAC-14 para quaisquer das doses de potássio aplicadas produziu mais grãos que o IAC-8. A produção do IAC-8 foi linearmente reduzida quando se aplicou potássio mas a do IAC-14 aumentou até a dose estimada de $29 \mathrm{~kg} \cdot \mathrm{ha}^{-1}$ de $\mathrm{K}_{2} \mathrm{O}$. (Tabela 10). Mascarenhas et al. (1976) relataram que não é comum a produção de grãos reagir positivamente à aplicação de potássio. Recomendam que mesmo assim a aplicação do nutriente seja feita normalmente para restituir o que foi retirado do solo, favorecendo a retenção de vagens e melhorando a qualidade da semente.

\section{CONCLUSÕES}

1) A inoculação não supriu adequadamente a absorção de nitrogênio pela soja quando verificada pela produtividade, teores de nitrogênio nas plantas e nos grãos.

2) Independentemente dos cultivares de soja utilizados e das localidades, a adubação nitrogenada promoveu decréscimo na nodulação (matéria seca e número de nódulos). No entanto, proporcionou acréscimos nos teores de nitrogênio acumulados na planta e nos grãos e maior produtividade.

2) Não se observaram respostas consistentes na quantidade da massa seca e número de nódulos, teor de nitrogênio nos grãos e rendimento de soja à adubação com potássio nos diferentes locais estudados.

\section{REFERÊNCIAS BIBLIOGRÁFICAS}

ANDRIOLO, J.; PEREIRA, P.A.A.; HENSON, R.A., 1994. Variabilidade entre Linhas de Formas Silvestres de Phaseolus vulgaris quanto a Características Relacionadas com a Fixação Biológica de $\mathrm{N}_{2}$. Pesquisa Agropecuária Brasileira, 29:831-837.

BARRON, J.E.; PASINI, R.J.; DAVIS, D.W.; STUTHMAN, D.D.; GRAHAM, P.H., 1999. Response to Selection for Seed Yield and Nitrogen $\left(\mathrm{N}_{2}\right)$ Fixation in Common Bean (Phaseolus vulgaris L.) Field Crops Research, 62:119-128. 
BATAGLIA, O.C.; TEIXEIRA, J.P.F.; FURLANI, P.R.; FURLANI, A.M.C.; GALLO, J.R., 1978. Análise Química de Plantas. Campinas: Instituto Agronômico, 31p. (Circular, 87).

BUIS, R.; BARTHOU, H.; ROUX, B., 1988. Effect of Temporary Chilling on Foliar and Caulinary Growth and Productivity in Soybean (Glycine max). Annals of Botany, 61:705-715.

CAMARGO, M.B.P., 1984. Exigências Bioclimáticas e Estimativa da

Produtividade para Quatro Cultivares de Soja no Estado de São

Paulo. Piracicaba, Tese de Mestrado, ESALQ, 96p.

CHEN, Z.; MACKENZIE, A.F., FANOUS, M.A., 1992. Soybean

Nodulation and Grain Yield as Influenced by N-Fertilizer Rate, Plant

Population Density and Cultivar in Southern Quebec. Canadian

Journal of Plant Science, 72:1049-1056.

DE MOOY, C.J.; PESEK, J., 1966. Nodulation Responses of Soybeans

to Added Phosphorus, Potassium and Calcium Salts. Agronomy

Journal, 58:275-280.

DUKE, S.H.; COLLINS, M., 1985. Role of Potassium in Legume

Dinitrogen Fixation. In: MUNSON, R.D. (ed.) Potassium in Agriculture. Madison: American Society of Agronomy, p.443-465. FRANCO, A.A.; DOBEREINER, J., 1967. Especificidade Hospedeira na Simbiose com Rhizobium - Feijão e Influência de Diferentes Nutrientes. Pesquisa Agropecuária Brasileira, 2:467-474.

GILLER, K.E.; WILSON, K.J., 1991. Nitrogen Fixation in Tropical

Croppings Systems. Wallingford: CAB. p.51-66.

HANWAY, J.J.; THOMPSON, H.E., 1971. How a Soybean Plant

Develops ? Ames: Iowa State University of Science and Technology.

Cooperative Extension Service. 17p. (Special Report, 53 ver.)

HANWAY, J.J.; WEBER, C.R., 1971. Dry Matter Accumulation in

Soybean (Glycine max (L.) Merril) Plants as Influenced by N, P, and

K Fertilization. Agronomy Journal, 63:203-266.

HENNING, A.A.; FRANÇA NETO, J.B., 1993. Secagem e Armazenamento de Soja. In: ARANTES, N.E.; SOUZA, P.I.M. Cultura da Soja nos Cerrados. Piracicaba: Potafós. p.437-463. HERRIDGE, D.; ROSE, I., 2000. Breeding for Enhanced Nitrogen 
Fixation in Crop Legumes. Field Crops Research, 65:229-248. KRZYZANOWSKI, F.C.; GILIOLI, J.L.; MIRANDA, L.C., 1993. Produção de Sementes nos Cerrados. In: ARANTES, N.E.; SOUZA,

P.I.M. Cultura da Soja nos Cerrados. Piracicaba: Potafós. p.333. MASCARENHAS, H.A.A., 1989. Abertura de Vagens de Soja, em Decorrência de Fatores Ambientais e de Deficiência de Potássio. Agronômico, 41:64-69.

MASCARENHAS, H.A.A., 1988. Deficiência de Potássio em Soja em

São Paulo, Melhor Entendimento do Problema e Soluções. Agronômico, 40:35-42.

MASCARENHAS, H.A.A.; BRAGA, N.R.; TISSELI FILHO, O.; MIRANDA, M.A.C.; ROSTON, A.J., 1976. Calagem e Adubação para a Soja. Campinas: Instituto Agronômico, 7p. (Circular, 51). MASCARENHAS, H.A.A; NEPTUNE, A.M.L.; MURAOKA, T.; BULISANI, E. A.; HIROCE, R., 1980. Absorção de Nutrientes por Cultivares de Soja (Glycine max (L.) Merril ). Revista Brasileira de Ciência do Solo, 4:92-96.

NOGUEIRA, M.C.S., 1991. Curso de Estatística Experimental Apli-

cada à Experimentação Agrícola. Piracicaba: ESALQ. 168p. OHLROGGE, A.J., 1960. Mineral Nutrition of Soybeans. Advances in Agronomy, 12:229-263.

RAPER JR; BARBER, S.A., 1970. Rooting System of Soybeans. II. Physiological Effectiveness as Nutrient Absorption Surfaces. Agronomy Journal, 62:585-588.

SINCLAIR, T.R.; SOFFES, A.R.; HINSON, K.; ALBRECHT, S.L.;

PFAHLER, P.L., 1991. Genotypic Variation in Soybean Nodule Number and Weight. Crop Science, 31:301-304.

SFREDO, G.J.; LANTMANN, A.F.; CAMPO, R.J.; BORKERT, C.M.,

1986. Soja: Nutrição Mineral, Adubação e Calagem. Londrina:

EMBRAPA - CNPSo, 51p. (Documentos, 17).

SIQUEIRA, J.O.; FRANCO, A.A., 1988. Biotecnologia do solo: Fundamentos e Perspectivas. Brasília: MEC, Ministério da Educação, ABEAS; Lavras: ESAL, FAEPE. p.206-207.

STAMFORD, N.P.; NEPTUNE, A.M.L.; SILVA, E.P., 1980. Efeito do 
Potássio em Presença de N-Mineral, na Nodulação, Crescimento e Absorção de Nutrientes por Vigna unguiculata (L.) Walp. Revista Brasileira de Ciência do Solo, 4:99-103.

TANAKA, A., 1985. The Physiology of Soybean Yield Improvement. In: SHANMUGASUNDARAM, S.; SULZBERGER, E.W. (ed.) Soybean in Tropical and Subtropical Cropping Systems. Shanhua: The Asian Vegetable Research and Development Center. p.323-331. (capítulo 44).

TANAKA, R.T.; MASCARENHAS, H.A.A., 1992. Soja: Nutrição, Correção do Solo e Adubação. Campinas: Fundação Cargill. 60p. VARGAS, M.A.; MENDES, I.C.; SUHET, R.; PERES, J.R.R., 1993. Fixação Biológica do Nitrogênio. In: ARANTES, N.E.; SOUZA, P.I.M. Cultura da Soja nos Cerrados. Piracicaba: Potafós. p.159182.

VASILAS, B.L.; FUHRMANN, J.J., 1993. Field Response of Soybean to Increased Dinitrogen Fixation. Crop Science, 33:785-787.

VERNETTTI, F.J., 1983. Bases Genéticas e Fisiológicas de Produção e Nutrição. VERNETTI, F.J. Soja. Campinas: Fundação Cargill. v.2, p.875-990.

YINBO, G.; PEOPLES, M.B.; PERKASEM, B., 1997. The Effect of N Fertilizer Strategy on $\mathrm{N}_{2}$ Fixation, Growth and Yield of Vegetable Soybean. Field Crops Research, 51:221-229.

YORINORI, J.T.; CHARCHAR, M.J. D'A; NASSER, L.C.B.; HENNING, A.A., 1993. Doença da Soja e Seu Controle. In: ARANTES, N.E.; SOUZA, P.I.M. Cultura da Soja nos Cerrados. Piracicaba: Potafós. p.333-397. 